\title{
Vinflunine - an active chemotherapy for treatment of advanced non-small-cell lung cancer previously treated with a platinum-based regimen: results of a phase II study
}

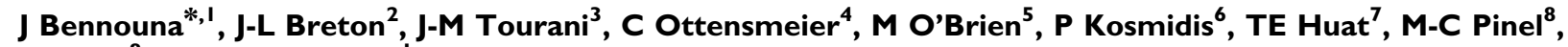 \\ C Colin ${ }^{8}$ and J-Y Douillard'
}

'Centre René Gauducheau, Boulevard Jacques Monod, Saint-Herblain 44805, France; ${ }^{2}$ Centre Hospitalier Général, Belfort, France; ${ }^{3}$ Centre Hospitalier Universitaire, Poitiers, France; ${ }^{4}$ Southampton University Hospitals, Southampton, UK; ${ }^{5}$ Royal Marsden Hospital, Sutton, UK; ${ }^{6}$ Hygeia Hospital, Athens, Greece; ${ }^{7}$ National Cancer Center, Singapore, Singapore; ${ }^{8}$ Institut de Recherche Pierre Fabre, Boulogne-Billancourt 92654, France

A multicentre, single-arm, phase II trial designed to determine the efficacy of single-agent vinflunine in patients with advanced nonsmall-cell lung cancer (NSCLC) previously treated with a platinum-based regimen. The objectives were to assess efficacy in terms of tumour response rate (primary end point), duration of response, progression-free survival (PFS) and overall survival (OS), and to evaluate the toxicity associated with this treatment. Patients with advanced NSCLC with progressive disease having failed prior platinum-based first-line treatment for advanced disease. Five responses out of the 63 treated patients were documented by $\mathrm{WHO}$ criteria and validated by an independent panel review (IRP), yielding a response rate of 7.9\% (95\% Cl: 2.6- 17.6) in the intent-to-treat analysis and $8.3 \%$ (95\% Cl: $2.8-18.4)$ in the evaluable population. Disease control was achieved in 35 out of 60 evaluable patients (58.3\%). The median duration of response (complete response + partial response), according to modified WHO criteria was 7.8 months (95\% Cl: $4.6-N R)$. Median PFS was 2.6 months (95\% Cl: $1.4-3.8$ ), and the median survival was 7.0 months (95\% Cl: $5.8-$ 9.2). Grades $3-4$ neutropenia was reported in $50 \%$ of patients; febrile neutropenia was observed in two patients (3.2\%); grades $3-4$ myalgia and grade 3 constipation were experienced by 10 (15.9\%) and six (9.5\%) of patients, respectively. Constipation was manageable, noncumulative and could be prevented with laxative prophylaxis. The encouraging results from this phase II study with vinflunine warrant further investigations in phase III trials as second- or first-line treatment of advanced non-small-cell lung carcinoma, as a single agent or in combination with other active drugs.

British Journal of Cancer (2006) 94, 1383- 1388. doi:10.1038/sj.bjc.6603106 www.bjcancer.com

Published online 25 April 2006

(C) 2006 Cancer Research UK

Keywords: vinflunine; phase II study; non-small-cell-lung-cancer

Patients with newly diagnosed inoperable stage (IIIB-IV) lung cancer and reasonable performance status should receive treatment with at least one chemotherapy regimen and it is now accepted that the schedule should be platinum based, in combination with a newer agent such as a taxane, vinorelbine or gemcitabine (Kelly et al, 2001; Schiller et al, 2002). The benefits of this approach are relatively modest; however, patients who progress on or after first-line chemotherapy for advanced disease but continue to be in good general condition may be offered second-line chemotherapy. Currently, three drugs are approved for second-line therapy of non-small-cell lung cancer (NSCLC) (docetaxel, erlotinib and pemetrexed), however, the life expectancy of these patients remains short and new drugs are urgently needed for this setting.

Vinflunine (Javlor ${ }^{\mathbb{R}}$, Pierre Fabre Médicament, Boulogne-Billancourt, France) is a novel tubulin-targeted agent obtained by

*Correspondence: Dr J Bennouna; E-mail: j-bennouna@nantes.fnclcc.fr Received 30 January 2006; revised 20 March 2006; accepted 20 March 2006; published online 25 April 2006 semisynthesis using superacidic chemistry to selectively introduce two fluorine atoms at the $20^{\prime}$ position of catharanthine moiety of vinca alkaloid (Fahy et al, 1997). The actions of vinflunine on microtubules produce effects on mitotic spindle functions leading to modifications of cell cycle progression and cell killing (Ngan et al, 2000) Vinflunine prevents microtubule assembly during mitosis (Etiévant et al, 1998; Kruczynski et al, 1998; Ngan et al, 2001). The affinity profile of vinflunine shows features which suggest that it will have greater effects on mitotic rather than axonal tubulin and so will not cause significant neurotoxicity (Lobert et al, 1998). Vinflunine showed antitumour activity in xenografts tested and high in vivo activity against the NCI H69 human NSCLC model (Hill et al, 1999; Kruczynski et al, 1999). Vinflunine treatment every 3 weeks was considered optimal, based on clinical and pharmacokinetic data from the three dose schedules evaluated in Phase I trials. Vinflunine was administered at the beginning of the phase I trials at $350 \mathrm{mg} \mathrm{m}^{-2}$ in normal saline as a 10-min infusion; after an early safety analysis this dose was adjusted at $320 \mathrm{mg} \mathrm{m}^{-2}$ which is the recommended dose for all subsequent patients included in clinical trials (Bennouna et al, 2003). The preclinical profile of vinflunine suggests that this first 
fluorinated antitubulin compound is a good candidate for secondline chemotherapy in patients with advanced NSCLC cancer after failure of standard platinum-based chemotherapy.

\section{MATERIALS AND METHODS}

\section{Objectives}

This study was an open-label, multicentre, nonrandomised phase II trial designed to determine the efficacy of vinflunine in patients with advanced NSCLC with clear evidence of metastatic disease who had failed platinum-based therapies for advanced disease. The primary objective was to measure response rate by WHO criteria; secondary objectives were to assess duration of response, progression-free survival (PFS) and overall survival (OS) and to evaluate the toxicity associated with this treatment. The protocol and its amendments were submitted to Independent Ethics Committees (IEC) according to local requirements. The study was conducted in accordance with the ethical principles set forth in the Declaration of Helsinki (Somerset West 1996) and in compliance with Good Clinical and Laboratory Practices. Written informed consent was obtained from each participating patient prior to entry into the study.

\section{Patient selection}

Patients were recruited from seven active centres between October 2001 and May 2003. Patients eligible for the study were required to have a histologically confirmed diagnosis of NSCLC cancer with clear radiological or clinical evidence of progressive disease (PD). Previous systemic chemotherapy or radiotherapy had to have been stopped 30 days before the administration of the study drug, and a full recovery from all side effects was necessary. The presence of at least one bidimensionally measurable lesion, not previously irradiated, assessed by CT-scan or MRI performed $<28$ days before 1st day of study drug administration was required. Patients were required to be aged $\geqslant 18$ years with Karnofsky Performance Status (KPS) $\geqslant 80$ and an estimated life expectancy of $\geqslant 12$ weeks. Evidence of adequate haematological function (absolute neutrophil count (ANC) $\geqslant 2.0 \times 10^{9} 1^{-1}$, platelets $\geqslant 100 \times 10^{9} 1^{-1}$ ), hepatic function (bilirubin $\leqslant 1.5 \times$ upper normal limit (UNL), transaminases $\leqslant 2.5 \times$ UNL, unless due to liver involvement), normal renal function and a normal ECG was required.

\section{Treatment schedule}

Vinflunine was given at the dose of $320 \mathrm{mg} \mathrm{m}^{-2}$ as a 10 -min infusion every 21 days. Tolerance was assessed throughout the treatment period and before each administration according to the NCI Common Toxicity Criteria (Version 2.0). All patients who received at least one vinflunine administration were considered as evaluable for safety. The use of haematopoietic growth factors (G-CSF) was allowed for patients with febrile neutropenia or neutropenic infections according to local guidelines. Vinflunine had to be delayed by 1 or 2 weeks in the case of haematological or nonhaematological toxicity (grade $>2$ toxicity impacting a major organ except for alopecia). If febrile neutropenia and/or a grade 4 neutropenia $\left(<1.0 \times 10^{9} 1^{-1}\right)$ lasting 7 days or more was observed between 2 subsequent administrations of vinflunine, the dose was reduced to $280 \mathrm{mg} \mathrm{m}^{-2}$ from the next cycle on. If, after a dose reduction, this toxicity was seen again with the same severity, the dose was further reduced to $250 \mathrm{mg} \mathrm{m}^{-2}$. If at this dose level the same event recurred, the treatment was stopped. Blood counts were to be performed every 2 days until recovery of ANC $\geqslant 1.0 \times 10^{9} 1^{-1}$. No dose re-escalation was allowed after dose reduction. In case of grade 2 mucositis and/or constipation lasting more than 5 days, or grade $\geqslant 3$ mucositis, and/or constipation of any duration, the vinflunine dose was reduced to $280 \mathrm{mg} \mathrm{m}^{-2}$ from the next cycle on. If, after dose reduction, one of these toxicities was seen again, the dose was reduced to $250 \mathrm{mg} \mathrm{m}^{-2}$. If at this dose the event recurred, the treatment was discontinued. Each patient had to receive at least two cycles of treatment unless early progression, unacceptable toxicity, serious intercurrent illness, other reactions occurred which could affect the clinical status of the patient to a significant degree requiring discontinuation of the drug, or request by the patient to withdraw consent.

After the initial two cycles, tumour response was assessed; for patients showing PD the treatment had to be discontinued; patients showing stable disease (SD) received two further cycles of vinflunine, after a second assessment treatment could be continued at the Investigator's discretion; patients presenting with a complete or a partial response (CR, PR) could continue treatment until $\mathrm{PD}$, toxicity or patient preference precluded further therapy.

\section{Baseline and treatment evaluation}

Preregistration assessments included a detailed medical history, CT-scan, MRI or physical examination (in case of superficial lymph node or skin nodule) for tumour assessment. All positive imaging procedures at study entry had to be repeated every 6 weeks. An assessment of symptoms was made at study entry and then throughout treatment. Physical examination and vital signs were assessed on day one of each cycle. A complete blood cell count (including a differential and platelet count) was taken at baseline (within a maximum of 7 days prior to study drug administration) and during treatment, before each cycle. Additional samplings were planned on day $8 \mathrm{~s}$ and 15 of each cycle: in case the ANC was $<1.0 \times 10^{9} 1^{-1}$, counts were repeated every 2 days until recovery to ANC $\geqslant 1.0 \times 10^{9} 1^{-1}$. Transaminases, alkaline phosphatases, total bilirubin, lactate dehydrogenase, creatinine, electrolytes including $\mathrm{Ca}^{2+}, \mathrm{Na}^{+}$and $\mathrm{K}^{+}$and total protein were assessed at every cycle. Electrocardiogram was to be performed and recorded prior to initial administration and repeated at every cycle.

If PD had not occurred during the study treatment period, all lesions were regularly assessed until disease progression. Efficacy was assessed by investigators and subsequently by an Independent Review Panel (IRP) using both the WHO criteria (World Health Organisation, 1979; Green and Weiss, 1992) and RECIST guidelines (Therasse et al, 2000); CR was defined as disappearance of all lesions clinically and radiologically. Partial response was defined as $\geqslant 50 \%$ reduction in the sum of the products of perpendicular diameters of all lesion measurements maintained for at least 4 weeks while no other type of lesion progressed or appeared. Stable disease was defined as $<50 \%$ reduction and $<25 \%$ increase in the sum of the products of perpendicular diameters of all lesion measurements maintained for at least 4 weeks while no other type of lesion progressed or appeared. All responses and disease stabilisations (if appropriate) were reviewed by an independent radiologist. The duration of response was calculated for patients with confirmed response (CR or PR) from the date of registration until the date of documented progression, start of new anticancer therapy, date of death, lost follow-up or last news. The PFS was defined as the time elapsed from registration until progression, death, lost follow-up or last news; survival was defined as the time elapsed from registration date to death or lost to follow-up, or last date the patient was known to be alive.

\section{Statistical analysis}

Sample size was based on a one-sample multiple testing procedure (Fleming, 1982). With 55 evaluable patients, a null hypothesis for the true response rate of $4 \%$ and an alternative hypothesis of $14 \%$, the type I error $\alpha$ was $5 \%$ and the type II error $\beta$ was less than $20 \%$. 
Continuous data were summarised using median, minimum and maximum values. Categorical data were presented in contingency tables with frequencies and percentages. Exact confidence intervals were calculated at the $95 \%$ level. Time dependent parameters were analysed using the Kaplan-Meier method and 95\% confidence interval for the median was reported.

Efficacy analyses were performed on the intent to treat and evaluable population. The primary efficacy parameter was response rate and included only confirmed CR and PR. The other efficacy parameters were duration of response, PFS and OS.

Safety analyses were performed on the population of patients having received at least one dose of study treatment. Worst NCI CTC grade for haematological and nonhaematological adverse events were presented.

All statistical analyses were carried out with 8.2 version of $S A S^{\circledR}$ (SAS Institute Inc., Cary, NC, USA) for Windows ${ }^{\circledR}$.

\section{RESULTS}

Sixty-six patients with advanced or metastatic NSCLC were included in this study. Three patients who were included but not treated as they presented with intercurrent serious conditions after signing informed consent, were not included in the analysis. In line with the ICH E9 guidelines in which it states that only treated patients should be reported, the intent-to-treat analysis therefore includes 63 patients; an additional three patients were found to be ineligible after enrolment, hence results will also be presented for the 60 evaluable patients.

\section{Evaluation of efficacy}

Demographic features of the patients are summarised in Table 1. As planned, all patients had previously received chemotherapy including platinum (cisplatin or carboplatin or both). All but two patients had received this chemotherapy for advanced disease. The median treatment-free interval after platinum-based chemotherapy was 4.4 months (range 0.5-30.2 months). All patients enrolled in the study had clear evidence of PD, $74.6 \%$ had two or more metastatic lesions at entry. According to WHO criteria, five responses out of the 63 treated patients were documented and validated by an IRP, yielding a response rate of 7.9\% (95\% CI: $2.6-$ $17.6)$ in the intent-to-treat analysis and $8.3 \%$ (95\% CI: $2.8-18.4)$ in the evaluable population. The previous treatment of these patients consisted of carboplatin plus paclitaxel for four patients and cisplatin plus gemcitabine for one patient. The response rate was also analysed by the IRP using RECIST criteria: six patients were assessed as responders, yielding a response rate of $9.5 \%$ (95\% CI: $3.6-19.6$ ) in the intent-to-treat analysis and 10\% (95\% CI: $3.8-$ 20.5 ) on the evaluable population as shown in Table 2. Disease control, that is the absence of PD (CR $+\mathrm{PR}+\mathrm{SD}$ by WHO criteria) was achieved in 35 patients out of the 60 evaluable $(58.3 \%)$ patients.

The median duration of response ( $\mathrm{CR}+\mathrm{PR})$, according to WHO criteria was 7.8 months (95\% CI: 4.6-NR). Median PFS was 2.6 months (95\% CI: 1.4-3.8). The median survival time was 7 months (95\% CI: 5.8-9.2) (Figures 1 and 2). Twenty-two patients (34.9\%) received at least one further chemotherapy after study discontinuation (16 patients received monotherapy as follows: docetaxel: 12 patients; gemcitabine: two patients; irinotecan: one patient; and experimental agent: one patient; six patients underwent further chemotherapy with a combination regimen; cisplatin-vinorelbine: two patients; gemcitabine-docetaxel, gemcitabine-carboplatin, mitomycin $\mathrm{C}$-vinblastine-cisplatin and docetaxel-carboplatin: one patient, respectively).

Table I Demographic data

\begin{tabular}{|c|c|c|}
\hline $\begin{array}{l}\text { Age (years) } \\
\text { Median } \\
\text { Range }\end{array}$ & $\begin{array}{c}61.6 \\
(38.7-78.7) \\
\text { Patients }(n=63)\end{array}$ & $\%$ \\
\hline \multicolumn{3}{|c|}{ - } \\
\hline Male & 47 & 74.6 \\
\hline Female & 16 & 25.4 \\
\hline \multicolumn{3}{|l|}{ Karnofsky PS Status } \\
\hline 100 & 14 & 22.2 \\
\hline 90 & 21 & 33.3 \\
\hline 80 & 28 & 44.4 \\
\hline \multicolumn{3}{|l|}{ Histopathologic type } \\
\hline Adenocarcinoma & 35 & 55.6 \\
\hline Squamous cell carcinoma & 18 & 28.6 \\
\hline Large cell carcinoma & 3 & 4.8 \\
\hline Not specified & 7 & 11.1 \\
\hline \multicolumn{3}{|l|}{ Treatment type } \\
\hline Chemotherapy alone & 38 & 60.3 \\
\hline Radiotherapy+chemotherapy & 11 & 17.5 \\
\hline Surgery+chemotherapy & 10 & 15.8 \\
\hline Surgery+radiotherapy+chemotherapy & 4 & 6.4 \\
\hline \multicolumn{3}{|l|}{ Chemotherapy } \\
\hline Carboplatin-paclitaxel & 15 & 23.8 \\
\hline Carboplatin-gemcitabine & 13 & 20.6 \\
\hline Carboplatin-docetaxel & 4 & 6.3 \\
\hline Carboplatin-vinorelbine & I & 1.6 \\
\hline Cisplatin-vinorelbine & 12 & 19 \\
\hline Cisplatin-gemcitabine & 8 & 12.7 \\
\hline Cisplatin-mitomycin C-vinblastine & 6 & 9.5 \\
\hline Cisplatin-mitomycin C-ifosfamide & 2 & 3.2 \\
\hline Carboplatin-docetaxel-gemcitabine & 1 & 1.6 \\
\hline Cisplatin-vinorelbine-ifosfamide & i & 1.6 \\
\hline
\end{tabular}

Table 2 Overall response rate

\begin{tabular}{|c|c|c|c|c|}
\hline & \multicolumn{2}{|c|}{ ITT population } & \multicolumn{2}{|c|}{ Evaluable population } \\
\hline & WHO & RECIST & WHO & RECIST \\
\hline Number of patients & 63 & 63 & 60 & 60 \\
\hline Complete response (CR) & - & - & - & - \\
\hline Partial response (PR) & $5(7.9 \%)$ & $6(9.5 \%)$ & $5(8.3 \%)$ & $6(10 \%)$ \\
\hline Overall response (CR+PR) & $5(7.9 \%)$ & $6(9.5 \%)$ & $5(8.3 \%)$ & $6(10 \%)$ \\
\hline $95 \%$ Confidence interval & $(2.6-17.6)$ & $(3.6-19.6)$ & $(2.8-18.4)$ & $(3.8-20.5)$ \\
\hline Stable disease & $31(49.2 \%)$ & $31(49.2 \%)$ & $30(50 \%)$ & $30(50 \%)$ \\
\hline Disease control $(\mathrm{CR}+\mathrm{PR}+\mathrm{NC})$ & $36(57.1 \%)$ & $37(58.7 \%)$ & $35(58.3 \%)$ & $35(58.3 \%)$ \\
\hline Disease progression (PD) & $25(39.7 \%)$ & $24(38.1 \%)$ & $25(41.7 \%)$ & $24(40 \%)$ \\
\hline Not evaluable & $2(3.2 \%)$ & $2(3.2 \%)$ & & \\
\hline
\end{tabular}




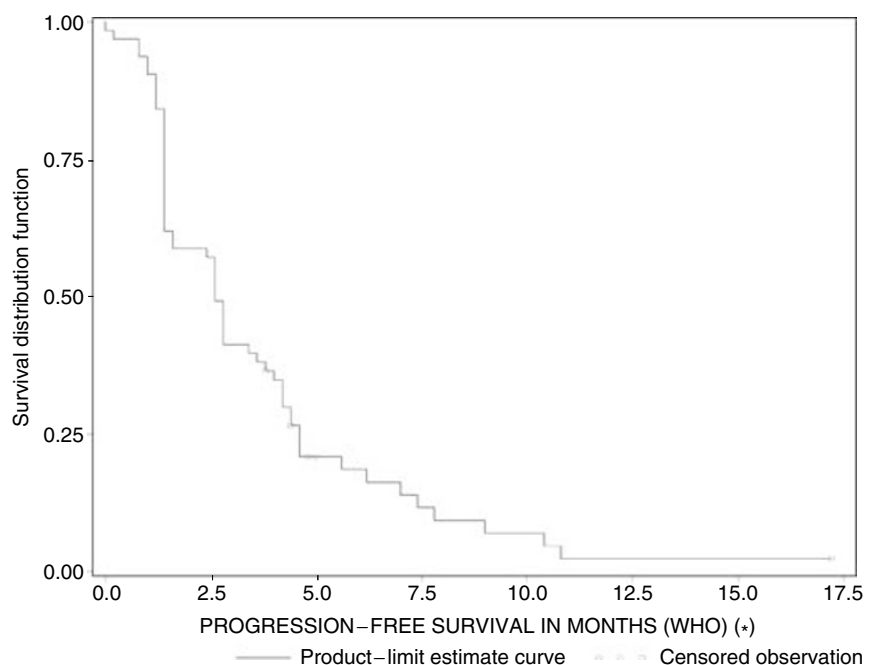

Figure I Progression-free survival.

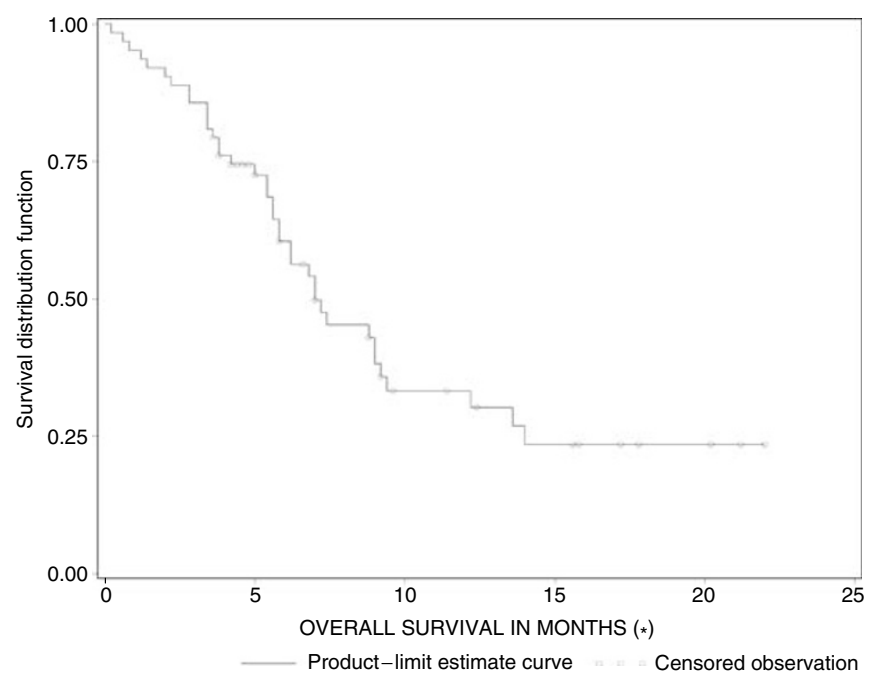

Figure 2 Overall survival.

Table 3 Haematological (NTC CTC, Version 2.0) drug-related adverse events

\begin{tabular}{|c|c|c|c|c|c|c|c|c|c|c|c|c|}
\hline \multirow{2}{*}{ Haematological } & \multicolumn{6}{|c|}{$N=62^{\mathrm{a}}$ patients } & \multicolumn{6}{|c|}{$N=22 I^{a}$ cycle } \\
\hline & \multicolumn{2}{|c|}{ Overall incidence } & \multicolumn{2}{|c|}{ Grade 3} & \multicolumn{2}{|c|}{ Grade 4} & \multicolumn{2}{|c|}{ Overall incidence } & \multicolumn{2}{|c|}{ Grade 3} & \multicolumn{2}{|c|}{ Grade 4} \\
\hline Anaemia & 55 & 88.7 & 4 & 6.5 & 0 & 0 & 177 & 80.1 & 4 & 1.8 & 0 & 0 \\
\hline Leucopenia & 53 & 85.5 & 15 & 24.2 & 5 & 8.1 & 147 & 66.5 & 25 & 11.3 & 7 & 3.2 \\
\hline Neutropenia & 51 & 82.3 & 16 & 25.8 & 15 & 24.2 & 150 & 67.9 & 35 & 15.8 & 23 & 10.4 \\
\hline Infection with $G 3 / 4$ neutropenia & 2 & 3.2 & 2 & 3.2 & 0 & 0 & 2 & 0.9 & 2 & 0.9 & 0 & 0 \\
\hline
\end{tabular}

${ }^{a}$ One patient was not evaluable for haematological toxicity.

Karnofsky Performance Status was recorded for each patient at baseline and before each treatment cycle during the study (i.e. every 3 weeks). Ten out of 63 patients $(15.9 \%)$ had an improvement of their KPS during treatment and $36(57.1 \%)$ maintained their baseline KPS. Only 15 patients $(23.8 \%)$ had a worsening KPS during treatment.

\section{Evaluation of safety}

The total number of cycles delivered was 223 (median number was 2 (range 1-9)). The median relative dose intensity by patient was $99.4 \%$ of the theoretical scheduled dose. Seventeen out of 63 patients $(27 \%)(32.5 \%$ of cycles) had dose reductions. Fourteen patients $(22.2 \%)$ had at least one cycle delayed; 20 cycles were postponed as follows: five delays $\geqslant 4$ days and $<7$ days, 11 delays between 7 and 14 days and four delays $\geqslant 14$ days. Six delays were due either to drug related haematological toxicity (four) or to drug-related nonhaematological toxicity (two); the other 14 cycles were postponed due to adverse events unrelated to the study drug and logistical or administrative issues.

Grade 3/4 neutropenia was observed in $50 \%$ of patients but only two patients experienced febrile neutropenia (3.2\%), and $3.2 \%$ neutropenic infection. No prophylactic growth factors were allowed. Although growth factors were permitted for the treatment of febrile neutropenia or grade 4 neutropenia without infection no patient in the study received this intervention. grade 3 anaemia was observed in $6.5 \%$ of patients but no grade 4 anaemia was reported; thrombocytopenia was rare (Table 3). Grade 3/4 myalgia was observed in $15.9 \%$ of patients; six out 63 patients suffered from grade 3 constipation (9.5\%) that was reported in five patients after the first dose; no grade 4 constipation was reported. Severe fatigue, arthralgia anorexia, abdominal pain and stomatitis were uncommon and observed in $<6 \%$ of patients (Table 4 ).

No clinical significant alterations in biological parameters were observed. (creatinine, total bilirubin, SGOT/AST, SGPT/ALT and alkaline phosphatase).

\section{DISCUSSION}

Although in 1997, ASCO guidelines stated that there was no current evidence that second-line chemotherapy improved survival with advanced NSCLC (American Society of Clinical Onology, 1997) there are now a number of trials which have demonstrated benefit for patients with disease progression after first-line chemotherapy (Biesma et al, 1999) including a number of studies which have documented a quality of life benefit (Dancey et al, 1999; Miller et al, 1999).

Results of the phase II study presented here have demonstrated that vinflunine has clinically relevant activity as second-line treatment of patients with NSCLC who have failed first-line treatment with a platinum-containing regimen. The overall response rate of $8 \%$ and a median OS of over 7 months compares favourably with reports in the literature on the use of best supportive care and of other new agents. At the current time only erlotinib, docetaxel and pemetrexed are approved for the 


\begin{tabular}{|c|c|c|c|c|c|c|c|c|c|c|c|c|}
\hline \multirow[b]{3}{*}{ Nonhaematological } & \multicolumn{6}{|c|}{$\mathbf{N}=\mathbf{6 3}$ pts } & \multicolumn{6}{|c|}{$N=223$ cycle } \\
\hline & \multicolumn{2}{|c|}{ Overall incidence } & \multicolumn{2}{|c|}{ Grade 3} & \multicolumn{2}{|c|}{ Grade 4} & \multicolumn{2}{|c|}{ Overall incidence } & \multicolumn{2}{|c|}{ Grade 3} & \multicolumn{2}{|c|}{ Grade 4} \\
\hline & $n$ & $\%$ & $n$ & $\%$ & $n$ & $\%$ & $n$ & $\%$ & $n$ & $\%$ & $n$ & $\%$ \\
\hline Cardiac ischaemia & I & 1.6 & 0 & 0 & I & 1.6 & I & 0.4 & 0 & 0 & 1 & 0.4 \\
\hline Thrombosis/embolism & I & 1.6 & 0 & 0 & I & 1.6 & 2 & 0.9 & 0 & 0 & 2 & 0.9 \\
\hline Fatigue & 34 & 54.0 & 3 & 4.8 & 1 & 1.6 & 85 & 38.1 & 3 & 1.3 & I & 0.4 \\
\hline Anorexia & 10 & 15.9 & 2 & 3.2 & 0 & 0 & 12 & 5.4 & 2 & 0.9 & 0 & 0 \\
\hline Constipation & 40 & 63.5 & 6 & 9.5 & 0 & 0 & 93 & 41.7 & 6 & 2.7 & 0 & 0 \\
\hline Gastritis & 3 & 4.8 & । & 1.6 & 0 & 0 & 5 & 2.2 & । & 0.4 & 0 & 0 \\
\hline Stomatitis & 26 & 41.3 & 2 & 3.2 & 1 & 1.6 & 42 & 18.8 & 2 & 0.9 & I & 0.4 \\
\hline Abdominal pain & 18 & 28.6 & 2 & 3.2 & 0 & 0 & 27 & 12.1 & 3 & 1.3 & 0 & 0 \\
\hline Arthralgia & 3 & 4.8 & 3 & 4.8 & 0 & 0 & 4 & 1.8 & 3 & 1.3 & 0 & 0 \\
\hline Chest pain & 8 & 12.7 & I & 1.6 & 0 & 0 & 12 & 5.4 & I & 0.4 & 0 & 0 \\
\hline Myalgia & 18 & 28.6 & 8 & 12.7 & 2 & 3.2 & 45 & 20.2 & 9 & 4 & 2 & 0.9 \\
\hline Neuropathic pain & 9 & 14.3 & 1 & 1.6 & 0 & 0 & 18 & 8.1 & I & 0.4 & 0 & 0 \\
\hline 2 & 2 & 3.2 & 1 & 1.6 & 0 & 0 & 3 & 1.3 & I & 0.4 & 0 & 0 \\
\hline ARDS & 1 & 1.6 & 0 & 0 & I & 1.6 & 1 & 0.4 & 0 & 0 & 1 & 0.4 \\
\hline
\end{tabular}

treatment of advanced, platinum-refractory non-small lung cancer. The application for broadening the indication of docetaxel to include second-line chemotherapy of patients with locally advanced or metastatic NSCLC was based on the results of a phase III study of docetaxel $v s$ vinorelbine/ifosfamide (Fossella et al, 2000) and another phase III study of docetaxel vs supportive care. The first study (Shepherd et al, 2000) failed to show a significant effect on the primary end point (OS), while it showed a significant increase in one secondary end point, the response rate, which was 10.5 and $6.5 \%$ for docetaxel 100 and $75 \mathrm{mg} \mathrm{m}^{-2}$, respectively, compared with $0.8 \%$ in the vinorelbine/ifosfamide. The study comparing docetaxel with supportive care in previously treated patients was analysed in two parts corresponding to two successive periods and doses of docetaxel: 100 and $75 \mathrm{mg} \mathrm{m}^{-2}$. In this study a significant increase in OS $(P=0.016)$ was observed. Docetaxel treatment also showed positive effects in several secondary endpoints of this study including the overall response rate of $6 \%$; time to progression was significantly improved in the overall docetaxel group (10.6 vs 6.7 weeks), as well as in docetaxel $75 \mathrm{mg} \mathrm{m}^{-2}$ (12.3 vs 7 weeks) and in docetaxel $100 \mathrm{mg} \mathrm{m}^{-2}$ subgroups (9.1 vs 5.9 weeks). The lower dose was generally better tolerated than in the higher dose. Recently, pemetrexed has demonstrated an overall response rate of $9 \%$ and 8-month median survival in a phase III trial comparing this drug with docetaxel; differences with the latter were generally limited to toxicity, with pemetrexed-treated patients experiencing less myelosuppression and fewer hospitalisations (Hanna et al, 2004). The double-blind placebo-controlled trial of erlotinib has shown that this drug significantly increases the PFS by 2 weeks and the OS by 2 months in comparison with best supportive care and placebo; the median OS of 6.7 months in erlotinib-treated patients in this trial is comparable with the results of the other agents (Shepherd et al, 2005). The role of gemcitabine and ixabepilone in the management of NSCLC patients who have failed first-line therapy is not yet clear due to the lack of phase III trial data in this setting (Rosvold et al, 1998; Vansteenkiste et al, 2003).

The toxicity profile of vinflunine is also acceptable by comparison with the other candidate agents; the most frequent adverse events observed were neutropenia in $50 \%$ of patients; however, only $3.2 \%$ developed febrile neutropenia; grade 3 constipation was observed in $9.5 \%$ of patients, but was manageable, noncumulative and could be prevented with prophylactic treatment.

The encouraging results from this phase II study with vinflunine warrant further investigations in phase III trials as second or first line treatment of advanced non-small cell lung carcinoma, as a single agent or in combination with other active drugs. Currently, a phase III trial comparing vinflunine with docetaxel in second-line treatment of NSCLC is ongoing.

\section{ACKNOWLEDGEMENTS}

This work was supported by Institut de Recherche Pierre Fabre, Boulogne-Billancourt, France. This work was previously presented in part as:

EH Tan, J Bennouna, C Ottensmeier, M O'Brien, P Kosmidis, MC Pinel, O Perrot, J-Y Douillard (2003). Vinflunine (VFL) in advanced non-small cell lung cancer (NSCLC): Preliminary results of a phase II study in patients previously treated with a platinum based regimen. Proc Am Soc Clin Oncol 22; abstract 2739.

EH Tan, J Bennouna, C Ottensmeier, M O’Brien, P Kosmidis, JL Breton, J-Y Douillard, JM Tourani, F Carballido, C Colin (2004). Phase II study of IV Vinflunine (VFL) as second line streatment of patients (pts) with advanced non-small-cell lung cancer (NSCLC) previously treated with a platinum based regimen - final results. Proc Am Soc Clin Oncol 23; abstract 7139.

\section{REFERENCES}

American Society of Clinical Oncology (1997) Clinical practice guidelines for the treatment of unresectable non-small cell lung cancer. J Clin Oncol 15: $2996-3018$

Bennouna J, Fumoleau P, Armand JP, Raymond E, Campone M, Delgado FM, Puozzo C, Marty ML (2003) Phase I and pharmacokinetic study of the new vinca alkaloid vinflunine administered as a $10-\mathrm{min}$ infusion every 3 weeks in patients with advanced solid tumours Ann. Ann Oncol 14: $630-637$

Biesma B, Smit EF, Postmus PE (1999) A dose and schedule finding study of gemcitabine and etoposide in patients with progressive non-small-cell lung cancer after platinum containing chemotherapy. Lung Cancer 24: $115-121$ 
Dancey J, Shepherd F, Ramlau R, Mattson K, Gressot L, O'Rourke M, Vincent M, Burkes R, Levitan N, Bergman B, Baez L, Rudd R, Kim Y, Coughlin S, Soussan-Lazard K, Gralla R (1999) Quality of life (QOL) assessment in a randomised study of taxotere (TAX) vs best supportive care (BSC) in non-small cell lung cancer (NSCLC) patients (pts) previously treated with platinum based chemotherapy. Proc Am Soc Clin Oncol 18: 491 (abstract 1896)

Etiévant C, Kruczynski A, Chansard N, Cabrol N, Astruc J, Chazottes E, Hill BTL (1998) Characterization of apoptosis induced by vinflunine, a novel fluorinated vinca alkaloid, in sensitive and vinflunine resistant P388 tumor cells: concomitant cell cycle analysis. Proc Am Assoc Cancer Res 39: 166

Fahy J, Duflos A, Ribet JP, Jacquesy JC, Berrier C, Jouannetaud MP, Zunino F (1997) Vinca alkaloids in superacidic media: a method for creating a new family of antitumor derivatives. J Am Chem Soc 36: 8576-8577

Fleming TR (1982) One-sample multiple testing procedure for phase II clinical trials. Biometrics 38: 143-151

Fossella FV, DeVore R, Kerr RN, Crawford J, Natale RR, Dunphy F, Kalman L, Miller V; Lee JS, Moore M, Gandara D, Karp K, Vokes E, Kris M, Kim Y, Gamza F, Hammershaimb L (2000) Phase III trial of docetaxel vs vinorelbine or ifosfamide in patients with advanced non-small-cell lung cancer previously treated with platinum-containing chemotherapy regimens. J Clin Oncol 18: 2354-2362

Green S, Weiss GR (1992) Southwest Oncology Group standard response criteria, endpoint definitions and toxicity criteria. Invest New Drugs 10: $239-253$

Hanna N, Shepherd FA, Fossella FV, Pereira JR, Marinis P, Pawel JV, Gatzemeier U, Muller T, Tsao CY, Pless M, Lim HL, Desch C, Szondy K, Gervais R, Shaharyar, Manegold C, Paul S, Paoletti P, Einhorn L, Bunn Jr PA (2004) Randomized phase III trial of pemetrexed $v s$ docetaxel in patients with non-small-cell lung cancer previously treated with chemotherapy. J Clin Oncol 22: 1589-1597

Hill BT, Fiebig HH, Waud WR, Poupon MF, Colpaert F, Kruczynski A (1999) Superior in vivo experimental antitumour activity of vinflunine, relative to vinorelbine, in a panel of human tumour xenografts. Eur J Cancer 35: $512-520$

Kelly K, Crowley J, Bunn Jr PA, Presant CA, Grevstad PK, Moinpour CM, Ramsey SD, Wozniak AJ, Weiss GR, Moore DF, Israel VK, Livingston RB, Gandara DR (2001) Randomized phase III trial of paclitaxel plus carboplatin $v s$ vinorelbine plus cisplatin in the treatment of patients with advanced non-small cell lung cancer: a Southwest Oncology Group trial. $J$ Clin Oncol 19: $3210-3218$

Kruczynski A, Astruc J, Ricome C, Colpaert F, Hill BT (1999) Definite antitumour activity of vinflunine, a novel fluorinated vinca alkaloid, against human tumour xenografts. Contrib Oncol Basel, Karger 54: 369-378

Kruczynski A, Barret JM, Etiévant C, Colpaert F, Fahy J, Hilll BT (1998) Antimitotic and tubulin-interacting properties of vinflunine, a novel vinca alkaloid. Biochem Pharmacol 55: 635-648
Lobert S, Ingram JW, Hill BT, Correia JJ (1998) A comparison of thermodynamic parameters for vinorelbine- and vinflunine-induced tubulin self-association by sedimentation velocity. Mol Pharmacol 53: $908-915$

Miller V, Fossella F, DeVore R, Kerr R, Crawford J, Karp D, Vokes E, Levitt M, Kim Y, Rodgers A, Hammershaimb L, Gamza F (1999) Docetaxel (D) benefits lung cancer symptoms and quality of life (QOL) in a randomized phase III study of non-small cell lung cancer (NSCLC) patients previously treated with platinum based therapy. Proc Am Soc Clin Oncol 18: 491 (abstract 1895)

Ngan VK, Bellman K, Hill BT, Wilson L, Jordan MAL (2001) Mechanism of mitotic block and inhibition of cell proliferation by semisynthetic vinca alkaloids vinorelbine and its new derivative vinflunine. Mol Pharmacol 60: $225-232$

Ngan VK, Bellman K, Panda D, Hill BT, Jordan MA, Wilson LL (2000) Novel actions of the antitumor drugs vinflunine and vinorelbine on microtubules. Cancer Res 60: 5045 - 5051

Rosvold E, Langer CJ, Schilder R, Milenson M, Reimet E, Kreamer K (1998) Salvage therapy with gemcitabine in advanced non-small-cell lung cancer (NSCLS progressing after prior carboplatin-paclitaxel). Proc Am Soc Clin Oncol 17: 467a (abstract 1797)

Schiller JH, Harrington D, Belani C, Langer C, Sandler A, Krook J, Zhu J, Johnson DH (2002) Comparison of four chemotherapy regimens for advanced non-small cell lung cancer. $N$ Engl J Med 346: $92-98$

Shepherd FA, Dancey J, Ramlau R, Mattson K, Gralla R, O’Rourke M, Levitan N, Gressot L, Vincent M, Burkes R, Coughlin S, Kim Y, Berille J (2000) Prospective randomized trial of docetaxel vs best supportive care in patients with non-small-cell lung cancer previously treated with platinum-based chemotherapy. J Clin Oncol 18: $2095-2103$

Shepherd FA, Pereira JR, Ciuleanu T, Tan EH, Hirsh V, Thongprasert S, Campos D, Maoleekoonpiroj S, Smylie M, Martins R, Van Kooten M, Dediu M, Findlay B, Tu D, Johnston D, Bezjak A, Clark G, Santabarbara P, Seymour L (2005) Erlotinib in previously treated non-small cell lung cancer. N Engl J Med 353: 123-132

Therasse P, Arbuck SG, Eisenhauer EA, Wanders J, Kaplan RS, Rubinstein L, Verweij J, Van Glabbeke M, Van Oosterom AT, Christian MC, Gwyther SG (2000) New guidelines to evaluate the response to treatment in solid tumors. J Natl Cancer Inst 92: 205-216

Vansteenkiste JF, Breton JL, Sandler A, Lara P, Paz-Ares L, Bonomi P, Le Chevalier T, Ardizzoni A, Peck R, Edelman M (2003) A randomised phase II study of epothilone analogue BMS-247550 in patients with nonsmall cell lung cancer who have failed first-line platinum-based chemotherapy. ProcAm Soc Clin Oncol 22: A2519

WHO Handbook for reporting results of cancer treatment, Geneva: World Health Organisation, 1979 